\title{
among youth in a general hospital in South Africa
}

\section{T. Mhlongo \\ MSc}

Student Councelling Centre University of Venda

\&

K. Peltzer

Ph.D.

Department of Psychology

University of the North

\section{"Research into both suicide and parasuicide among black South Africans was largely neglected"}

\begin{abstract}
Parasuicide cases among youth (15-24 years) referred to the clinical psychology section of a regional hospital from 1995 to 1998 were reviewed. In all 100 cases (37 males and 63 females) were identified being about $10 \%$ of the caseload. As part of the clinical psychological assessment sociodemographic, clinical characteristics, trigger factors, employed methods and suicide intentions were analysed. Most patients were students $(79 \%)$ or unemployed $(16 \%)$. The major method employed to attempt suicide was ingestion of harmful substances (like paraffin, pesticides or battery acid)( $73 \%)$. Acute social conflicts $(38 \%)$, socio-economic deprivation (17\%), AIDS phobia (17\%), academic failure $(14 \%)$, teenage pregnancy $(10 \%)$ and mental illness $(5 \%)$ triggered suicide attempts. Fifty-eight percent of the attempts were categorised as demonstrative and $27 \%$ as genuine. The psychodynamics of parasuicides are discussed in case studies and with reference to other studies.
\end{abstract}

\section{Introduction}

Parasuicide among the youth has become a very real problem in hospitals and society in general today in South Africa (Naidoo \& Pillay 1993: 979, Schlebusch 1985: 792). The rate of suicidal behaviour has increased dramatically in the last 30 years, the largest increase being in the age group 15-24 years old (Diekstra 1989: 18-22). Schlebusch (1985: 793) reports that $17.7 \%$ of general hospital admissions in Durban were patients referred because of parasuicide. Nearly one-third (29\%) of the parasuicides were young patients, i.e. of 19 years old and younger, which represented a notable increase (by $5 \%$ ) within the last 5 years.

There has been a widely held view that suicidal behaviour is a peculiarity of western industrialised societies. In recent years there is convincing evidence that in all cultures and societies, irrespective of their stage of development, suicidal behaviour occurs (Diekstra 1989: 17). Studies in most African countries indicate that the rate of suicide and parasuicide is reported to be less than 1:100000 per year (Jacobsson 1985: 596). However, statistics for parasuicides among blacks are probably inaccurate as under reporting is likely to occur for a number of reasons interalia the shortage or inaccessibility of health facilities (Naidoo \& Pillay 1993: 979).

Research into both suicide and parasuicide among black South Africans was largely neglected, despite socioeconomic and gross socio-political (e.g., political unrest, township murders, and taxi wars) factors that they were exposed to. However, there are numerous published studies about other population groups (Whites, Indians and 'Coloureds') (e.g. Pillay \& Wassenaar 1997: 228). Suicide attempts rather than completed suicides have increased most in the youngest age group. The Department of Education (1997) in the Northern Province of South Africa reports high rates of suicide and parasuicides among secondary school pupils. In a study among South African Secondary School pupils it was found that $34(17 \%)$ males and $31(13 \%)$ females had a history of attempted suicide. Major intentions or causes to commit suicide mentioned were "failing to solve problems" and "mental illness", and major possible suicide methods were firearms and pills/ poison (Peltzer, Cherian \& Cherian 1998 : 1262). Major contributing factors for the occurrence of parasuicides among youth in South Africa include chronic mental and physical illnesses, high un- 
employment rate, urbanisation, transition, acute social conflicts and access to means. Migrant labour mobility and the break of traditional family structures, alcohol abuse, and other deprivations are among frequent predisposing factors to parasuicide (Pillay \& Wassenaar 1997).

Parasuicide is one of the commonest emergencies in hospital practice, especially for the age group 19-24 years (Jacobsson 1985: 596, Ndosi \& Waziri 1997: 56). From clinical observations, suicide attempts in Letaba Hospital, South Africa, appear to be on the rise. Therefore this study aims at finding out the nature of suicide attempts in Letaba, the contributory risk factors and the psychosocial circumstances surrounding the act.

\section{Method}

\section{Sample and procedure}

The sample was drawn from the clinical psychology section (part of the psychiatry section with only a psychiatrist visiting once a week) at a regional general hospital (Letaba) in the Northern Province (South Africa). All cases of parasuicide among youth, between 16 and 24 years, referred to the clinical psychologist (first author) from 1995 to 1998 participated in the study.

In all 100 cases were identified from the medical wards or the casualty department being about $10 \%$ of the clinical psychological caseload. When the patients had recovered from adverse effects of parasuicide and had attained full consciousness, the purpose of the study was explained to patients and close relatives. Informed consent to participate in the study was sought from the patient (with parental assistance where applicable). The total sample was 100 suicide attempters ( 37 males and 63 females) and their mean age was 20.2 years $(S D=3.1)$. The ethnicity was 72 Tsonga and 28 Northern Sotho.

Permission to publish the data was obtained from the Department of Health and Welfare, Northern Province, and the Senior Medical Superintendent of Letaba nospital. Case studies presented here have been written by omitting aspects specifying their identity.

\section{Instruments}

Data were obtained from the patients, relatives, medical staff, medical records and other witnesses where necessary. Each patient was carefully assessed on the basis of a clinical interview and mental status examination. Clinical psychological assessments of the patient (and relative) included history of suicide in the family, the kinds and amounts of substance abuse, psychosocial and family circumstances as well as the motives and risk factors surrounding the parasuicide. In addition, sociodemographic background (age, gender, religion, ethnicity, occupation and education of parents) and family background (family size, birth order, psychodynamics) were assessed.

DSM - III-R criteria were used to formulate a diagnosis. Parasuicide was defined as behaviours that can vary from what are sometime called suicidal gestures and manipulative attempts to serious but unsuccessful attempts to kill oneself. It refers to any deliberate act with non-fatal outcome that attempts to cause or actually causes self-harm or without intervention from others would have done so, or what consists of ingesting a substance in excess of its generally recognised or prescribed therapeutic dose (Diekstra \& Gulbinat 1993: 52).

In a number of cases the patient was also seen by a visiting psychiatrist so as to confirm and improve the reliability of the diagnosis.

\section{Results}

From the one hundred suicide attempters 63 were female and 37 were male, 90 were single and 10 married, and 79 were churchgoers whereas 21 did not go to church. Table 1 indicates the employment status and educational level. Most of the suicide attempters were students (79) and 78 had at least 6 years of schooling.
Table 4 indicates the intentions of suicide attempters with 58 demonstrations and 27 as death wishes.

\section{Case studies}

\section{Case 1}

$F$ is an eighteen year old girl. A relative brought her to hospital casualty department, after she had ingested paraffin. She is doing her matric and attends church every Sunday. She is a child born out of wedlock, her biological parents separated before she was even born. Her mother married another man when she was eight years old, and her maternal grandparents brought her up. When she turned fifteen years old, her mother decided that she should stay with them (mother, stepfather and two half-brothers, aged seven and five years old).

F. states that her stepfather has never liked her, because he always criticised her. When she was sixteen years old, she discovered her biological father. She was actually told by her schoolmates that she looks like a certain man, she then went to talk to this man on her own. The man agreed that he is her biological father He was very happy and was willing to help her financially when she passed her matric. Her mother did not like the idea and was always shouting at her whenever she mentioned the biological father. Her stepfather threatened to chase her out of his house if she continues to see her biological father. She also stated that her mother and stepfather made her life

\section{Table 1 : Employment status and educational level of suicide attempts}

\begin{tabular}{|l|c|l|c|}
\hline Employment status & Number & Educational level & Number \\
\hline Employed & 05 & $0-6$ years & 26 \\
Unemployed & 16 & $7-12$ years & 78 \\
Students & 79 & 13 plus & 06 \\
\hline
\end{tabular}

Table 2 indicates the means employed to commit suicide.

The most commonly used method to commit suicide was paraffin (36) whereas three patients only used medicaments. The main trig. gers identified to commit suicide were mainly problems with parents and relationship but also AIDS phobia and academic failure (see Table 3).

\section{Table 2 : Means employed by suicide attempters}

\begin{tabular}{|l|c|}
\hline Means & Number \\
\hline Paraffin & 36 \\
Methylated spirit & 12 \\
Shampoo & 11 \\
Pesticides & 10 \\
Detergents & 09 \\
Battery acid & 06 \\
Hanging & 09 \\
Ingestion of glass & 04 \\
Medicaments & 03 \\
\hline
\end{tabular}




\section{Table 3 : Triggers of attempted suicide}

\begin{tabular}{|l|c|}
\hline Trigger & Number \\
\hline Problem with parents & 22 \\
AlDS phobia & 17 \\
Relationship problems & 16 \\
Academic failure & 14 \\
Teenage pregnancy & 10 \\
Unemployment & 09 \\
Financial problems & 08 \\
Mental illness & 05 \\
\hline
\end{tabular}

\section{Table 4 : Intentions of suicide attempters}

\begin{tabular}{|l|c|}
\hline Intentions & Number \\
\hline Demonstrations & 58 \\
Death wish & 27 \\
Uncertain motive & 15 \\
\hline
\end{tabular}

very difficult; they did not allow her friends to visit her nor her to visit their homes anymore.

Then F.'s biological father died in a motor vehicle accident and she was not allowed to attend his funeral. She also felt that her mother and stepfather were happy about her biological father's death. One day she requested money from her mother to buy a book for her school project. Then her mother made the remark that she should go to her (biological) father who used to give her lots of money. She stated that this made her very angry and hurt. She then went to her maternal aunt's place. When she was there, she saw a bottle with paraffin, took it and drank it. She mentioned that she did not plan to attempt suicide, but felt hopeless and helpless.

\section{Case 2}

$\mathrm{T}$. is a sixteen years old boy who was rushed to hospital as an emergency due to battery acid intake. The clinical psychologist saw him two days after the incident. He initially did not want to talk, and said we should ask his father questions regarding this incident. $\mathrm{He}$, however, started to talk that his father does not understand him and that he attempted suicide after he had quarrelled with his father. His father was accusing him of mixing with wrong people, coming home late at night and not taking good care of his siblings.

His father is a migrant labourer who comes home once every month. His mother is a domestic worker at a nearby town and only goes home during weekends. T. is a first born child in a family of five children. During his parents' absence he is taking care of his siblings. $\mathrm{He}$ is doing his matric and does not attend church.

He alleges that his parents, particularly his father are not thankful. He stated that he takes well care of his siblings and always handles the money very well that his parents give to him for the family. He always buys things for his siblings first, and would only buy for himself if there would be enough money left. He also felt that his father does not move with times, as his friends' parents never shout at them when they come late at night during weekends.

T. stated that before the incident, he always felt down whenever his father was around. He also felt that his mother does not protect him, she just kept quiet. He attempted suicide in order to leave the family alone. His parents were shocked by his suicide attempt, and they suspected witchcraft. He however felt that he was not bewitched, but just wanted them to understand his problem.

\section{Case 3}

$O$. is a 23 years old female who was brought to hospital after she was seen drinking shampoo. She was said to have behaved in a strange manner a few hours before she attempted suicide. She has been diagnosed with bipolar mood disorder and is taking treatment at the community psychiatric clinic. Her parents died in a motor vehicle accident when she was ten years old. She is staying with her maternal uncle and his fam. ily. She is doing grade 10 , and does not attend church

O. stated that she was not happy about her life. People were always laughing at her. She wanted to die so that they will not have anyone to laugh at. She had just discovered that she is three months pregnant, and when she told her boyfriend the news, he just laughed at her.

\section{Case 4}

C. is a twenty-two years old university student, who was brought to hospital by a local high school principal. He was doing his fourth year degree in educa- tion and was busy with his teaching practical. He was found sleeping at the school laboratory. One of his colleagues also doing teaching practical, told the school principal that C.'s girlfriend had just ended their three-year-old relationship. C. did not want to discuss this matter. He however fell off the chair while the principal was talking to him. He was rushed to hospital, where he mentioned that he had ingested different types of medication.

When he was physically stabilised, he was referred to the clinical psychologist. He stated that he drank more or less forty different tablets that were once prescribed for him or his family members. His mother is a teacher and his father died of suicide, when he was five years old. He is the last born son in a family of four children, the others are all girls. He attends church whenever he has the time. He stated that he felt very betrayed and disappointed by his girlfriend. He felt that life would not be the same without her.

\section{Discussion}

The discussion is divided into gender, intention/causes, and methods employed and contributing factors.

\section{Gender}

The higher rate of parasuicide in females than in males is consistent with findings in other studies (e.g. Diekstra \& Gulbinat 1993: 54, Minnaar, Schlebusch \& Levin 1980: 205, Spirito, Bond, Kurkjian et al. 1993: 178-180). Men were noted to use relatively dangerous methods (e.g., hanging), and they also attempted suicide when they were alone (not seen by others). On the other hand females were noted to use relatively less dangerous methods (e.g., drinking shampoo), and they were likely to attempt suicide in the presence of a significant other.

\section{Intentions/causes}

In this study intentionality is described in terms of demonstrations (58 cases) death wish (27), while 27 had an uncertain motive. The parasuicides also appear to have been mainly impulsive. committed during a row with a significant other person. The intention is usually confused and remembered poorly afterwards, as I just wanted to get out of the situation. Cheetham, Edwards, Naidoo et al. (1983: 945) argue that the use of ingestion of drugs and other toxic substances, results from a wish to escape high levels of tension among patients of low suicide intent. Ovuga and Mugisha (1990: 67f.) state that intentionality has to be thoroughly assessed, as most people who complete suicide have a history of suicide attempt.

Perceived suicide intentions in this study 
mainly refer to social stressors, dreadful disease and mental disturbance, which is similar to findings on parasuicides in other African samples. For example, the reported triggers of attempted suicide in Tanzania was $80.7 \%$ social conflicts, $8,3 \%$ financial problems, $5 \%$ chronic mental illness, $4,3 \%$ chronic physical illness and $1.6 \%$ bereavement $(n=300)$ (Ndosi \& Waziri 1997: 57) and Lusaka, Zambia, domestic quarrels, mental illness and physical diseases (Rwegellera 1978: 423).

\section{Methods employed}

The major method employed to attempt suicide was ingestion of harmful substances (e.g., paraffin, pesticides, and battery acid); this is similar to other studies (Minnaar et al. 1980: 205, Naidoo \& Pillay 1993: 980; Ndosi \& Waziri 1997:57, Panizzo 1994: 117, Wilson \& Wormald 1995: 529). This confirms Naidoo and Pillay's (1993: 981) findings that availability of substances overrides selection by choice. Furthermore, this also highlights that the youth live in poor conditions.

\section{Contributing Factors}

Similar to other studies (Pillay \& Pillay 1987: 259, Pillay \& Wassenaar 1995: 389 , Pillay \& Wassenaar 1997: 229) the contributing factors were noted to be unemployment, problems with parents, relationship problems, academic failure, teenage pregnancy, financial problems and mental illness, apart from AIDS phobia. However, factors such as substance abuse, history of sexual abuse, were not identified as trigger factors like in other studies (e.g. Ovuga, Buga \& Guwatudde 1995: 723f.). It was also noted that although depression was not reported to be a contributory factor in these suicide attempts, some youth did experience feelings of hopelessness and helplessness prior to the suicide attempt. The case studies described here also highlight that the youth attempted suicide as a way to cope with tension in their lives. No studies have been conducted in South Africa to explain the increase of parasuicide among blacks. However, factors related to an increase of suicide in South Africa seem to be a number of social stresses associated with changes taking place including increased divorce rate, increased unemployment rate, and increased homicide rate (Wassenaar et al. 1988, see also Diekstra 1989: 28.), Diekstra \& Garnefski 1995: 42t.). Diekstra (1989: 30) states that youth suicide attempters report more overall negative stress: parental absence, parental loss, authoritarian parenting, family conflicts, knowing someone who completed suicide, break-up of a romantic relationship and mental disturbance, are the personal stressors experienced by youth in these case studies. This study found those specific disturbances in family communication and problem solving may cause parasuicide. Social factors play an important role, if not a decisive role in the causation of parasuicide. Suicidal behaviour needs to be understood within a broad social context. The families usually have high unemployment and increased economic and emotional interdependence (Naidoo \& Pillay 1993: 981). The phenomenon of depression and suicide must also be located within this context of the disintegration of social structures due to the apartheid systems, migrant labour and uncertainties regarding transition taking place in South Africa.

Future research may address the role of religion and culture in suicide acceptability. Platt (1989: 137) found that high parasuicide rates in certain areas are characterized by a distinctive subculture that facilitates parasuicidal behaviour. Gijana, Louw \& Manganyi (1989/90: 255) found in a black South African sample that $90 \%$ expressed a negative attitude toward taking one's own life. There are no educational programmes or specific services available for the youth in the Northern Province of South Africa to prevent youth suicide. There is need to conduct further research with a view to plan health education programmes in schools and community organizations. 


\section{References}

CHEETHAM R.W.S., EDWARDS S.D., NAIDOO L.R., GRIFFITH J.A., \& SINGH V.G. 1983. Deculturation as a precipitant of parasuicide in an Asian group. South African Medical Journal 63: 942-945.

DIEKSTRA R.F.W. 1989. Suicidal behaviour in adolescents and young adults: the international picture. Crisis 10: 16-35.

DIEKSTRA R.F.W., \& GARNEFSKI N. 1995. On the nature, magnitude, and causality of suicidal behaviours: an international perspective. Suicide and Life-Threatening Behaviour 25 36-57.

DIEKSTRA R.F.W., \& GULBINAT W. 1993. The epidemiology of suicidal behaviour: a review of three continents. World Health Statistical Quarterly 46: 52-68.

GIJANA E.W.M., LOUW J., \& MANGANYI N.C . 1989/90. Thoughts about death and dying in an African sample. OMEGA 20: $245-258$

JACOBSSON L. 1985. Suicide and attempted suicide in a general hospital in western Ethiopia. Acta Psychiatrica Scandinavia 71: 596-600.

MINNAAR G.K., SCHLEBUSCH L., \& LEVIN A. 1980. A current study of parasucide in Durban. South African Medical Journal 57: 204-207.

NAIDOO P., \& PILLAY B.J. 1993. Parasuicide in a general hospital in South Africa. Psychological Reports 72: 979-982.

NDOSI, N.K., \& WAZIRI, M.C. 1997. The nature of parasuicide in Dar Es Salaam, Tanzania. Social Science \& Medicine 44: 55-61.

OVUGA E.B.L., \& MUGISHA R.X. 1990. Attitudes and psychological characteristics of suicidal individuals. Crisis 11: 6072 .

OVUGA E.B.L., BUGA J.W., \& GUWATUDDE D. 1995. Risk factors towards self-destructive behaviour among fresh students at Makerere University. East African Medical Journal 72: 722-727.

PANIZZO E. 1994. Study on suicide attempts analysed in the psychiatric ward of Maputo central hospital in 1990: psychological considerations. Psychopathologie Africaine 25: 109120.

PELTZER K., CHERIAN V.I., \& CHERIAN L . 1998. Attitudes toward suicide among South African Secondary School pupils. Psychological Reports 83: 1259-1265.

PILLAY A.L., \& PILLAY Y.G. 1987. A study of deliberate selfharm at a Pietermaritzburg general hospital. South African Medical Journal 72: 258-259.

PILLAY A.L., \& WASSENAAR D.R. 1995. Psychological intervention, spontaneous remission, hopelessness, and psychiatric disturbance in adolescent parasuicides. Suicide and Life-Threatening Behaviour 25: 386-392.

PILLAY A.L., \& WASSENAAR D.R. 1997. Family dynamics, hopelessness and psychiatric disturbance in parasuicidal adolescents. Australian and New Zealand Journal of Psychiatry 31: 227-231.
PLATT S. 1989. A subculture of parasuicide? In RFW Diekstra, R Maris, S Platt, A Schmidtke \& G Sonneck (eds.) Suicide and its prevention (pp. 108-143). Leiden: Brill.

RWEGELLERA G.G.C. 1978. Suicide rates in Lusaka: preliminary observations. Psychological Medicine 8: 423-432.

SCHLEBUSCH L. 1985. Self-destructive behaviour in adolescents. South African Medical Journal 68: 792-5.

SCHLEBUSH L., \& WESSELS W.H. 1988. Hopelessness and low-intent in parasuicide. General Hospital Psychiatry 10: 209213

SPIRITO. .A, BOND A., KURKJIAN J., DEVOST L., BOSWORTH T., \& BROWN L.K. 1993. Gender differences among adolescent suicide attempters. Crisis 14: 178-183.

WHITE G.L., MURDOCK R.T., RICHARDSON G.E., ELLIS G.D., \& SCHMIDT L.J. 1990. Development of a tool to assess suicide risk factors in urban adolescents. Adolescence 25: $657-666$

WILSON K.G., STELZER J., BERGMAN J.N., KRAL M.J., INAYATULLAH M., \& ELLIOTT C.A. 1995. Problem solving, stress, and coping in adolescent suicide attempts. Suicide and Life-Threatening Behaviour 25: 241-252.

WILSON D.A.B., \& WORMALD P.J. 1995. Battery acid ? an agent of attempted suicide in black South Africans. South African Medical Journal 85: 529-530. 